\title{
CORRECTION
}

View Article Online

View Journal I View Issue

\section{Correction: Individual single-crystal nanowires as electrodes for organic single-crystal nanodevices}

Cite this: J. Mater. Chem. C, 2015,

3, 9749

Guorui Wang, ${ }^{a}$ Qingxin Tang, ${ }^{a}$ Yanhong Tong, ${ }^{a}$ Wenping Hu${ }^{\star b}$ and Yichun Liu*a

Correction for 'Individual single-crystal nanowires as electrodes for organic single-crystal nanodevices'

DOI: $10.1039 / c 5 t c 90164 b$

by Guorui Wang et al., J. Mater. Chem. C, 2015, DOI: 10.1039/c5tc01920f.

www.rsc.org/MaterialsC

The equation for calculating mobility in the saturated regime $\left(I_{\mathrm{SD}}\right)$ in the last sentence of the experimental section on the second page of this article contained some errors. The correct version is as follows:

$$
I_{\mathrm{SD}}=\frac{W}{2 L} \cdot \mu C_{\mathrm{i}}\left(V_{\mathrm{G}}-V_{\mathrm{T}}\right)^{2}
$$

where $W$ is the channel width, $L$ is the channel length, $C_{\mathrm{i}}$ is the dielectric unit area capacitance, $\mu$ is field-effect mobility, $V_{\mathrm{G}}$ is gate voltage, and $V_{\mathrm{T}}$ is the threshold voltage.

The Royal Society of Chemistry apologises for these errors and any consequent inconvenience to authors and readers.

\footnotetext{
${ }^{a}$ Key Laboratory of UV Light Emitting Materials and Technology under Ministry of Education, Northeast Normal University, Changchun 130024, P. R. China. E-mail: tangqx@nenu.edu.cn, tongyh@nenu.edu.cn, ycliu@nenu.edu.cn; Fax:+86-431-85099873; Tel: +86-431-85099873

${ }^{b}$ Beijing National Laboratory for Molecular Sciences, Key Laboratory of Organic Solids, Institute of Chemistry, Chinese Academy of Sciences, Beijing 100190, P. R. China. E-mail: huwp@iccas.ac.cn
} 